\title{
Análise da produção escrita de surdos alfabetizados com proposta bilíngue: implicações para a prática pedagógica
}

An Analysis Of Deaf Students' Writing Who

were Taught Through Bilingual Process:

Implications For Teaching Practice

Eliziane Manosso Streiechen*

Universidade Estadual do Centro-Oeste

Irati - Paraná / Brasil

Cibele Krause-Lemke**

Universidade Estadual do Centro-Oeste

Irati - Paraná / Brasil

RESUMO: Este artigo tem como objetivo trazer algumas reflexōes sobre o processo de escrita de alunos surdos, apontando possíveis implicações para as práticas pedagógicas em ambientes inclusivos. Para isso serão analisados cinco textos produzidos por alunos surdos, alfabetizados por meio da metodologia bilíngue em uma escola pública do interior do Estado do Paraná. Trata-se de uma pesquisa qualitativa e, quanto ao tipo, classifica-se como estudo descritivo de caráter exploratório. A partir das análises dos textos, foi possível observar que os alunos surdos apresentam, em sua escrita, particularidades relacionadas à língua de sinais as quais podem incidir na estrutura sintática da Língua Portuguesa. A análise tenta descrever a estrutura da Libras em relação à Língua Portuguesa, com o objetivo de desvelar como se dá o processo de escrita por alunos surdos e, assim, apresentar possíveis estratégias que podem servir de suporte para os profissionais da educação ao lidar com este tipo de produção.

PALAVRAS-CHAVE: Língua de Sinais, Metodologia Bilíngue, Inclusão, Surdos.

ABSTRACT: This paper aims at bringing some reflection on the writing process of deaf students, pointing out possible implications for teaching practice in inclusive environments. Thereby, five written texts produced by deaf students will be analyzed. These students were taught how to write and read through

*lizi.unicentro@yahoo.com.br

**cibelekl@gmail.com 
bilingual methodology in a public school in the state of Paraná. This study has a qualitative method and is classified as an exploratory descriptive study. From the analysis of the texts, it is observed that deaf students' writing has some particularities related to the Brazilian sign language (also known as Libras), which can influence the syntactic structure of the Portuguese language. The analysis attempts to describe the structure of Libras in relation to the structure of Portuguese, with the aim of unveiling how the writing process by deaf students occurs and, thus, presenting possible strategies that could support education professionals who deal with this kind of production.

KEYWORDS: Sign Language, Bilingual Method, Inclusion. Deafs.

\section{INTRODUÇÃO}

Este texto tem como objetivo principal discutir a elaboração da escrita de alunos surdos que passaram por um processo de alfabetização com proposta bilíngue.

$\mathrm{Na}$ primeira parte, tratamos de alguns aspectos relacionados à aquisição da escrita em português por alunos surdos, bem como discorremos sobre a metodologia bilíngue e suas aplicações no contexto escolar inclusivo. $\mathrm{Na}$ segunda, apresentamos a metodologia utilizada. Já na terceira, analisamos alguns textos produzidos por alunos surdos, nos quais se evidencia o processo de aquisição da escrita em português e, por fim, nas considerações finais, apresentamos algumas implicações da pesquisa realizada para as práticas docentes que envolvem alunos surdos, a partir da metodologia de trabalho aplicada.

\section{A AQUISIÇÃO DA ESCRITA POR SURDOS E A METODO- LOGIA BILÍNGUE}

A aquisição da linguagem escrita pelos alunos surdos tem sido motivo de grande preocupação para professores que trabalham na área da surdez ou com alunos em processo de inclusão. Inúmeros questionamentos têm surgido a respeito das estratégias metodológicas a serem utilizadas na produção de textos escritos e, também, em relação aos critérios que devem ser considerados no momento da avaliação desses alunos.

Por isso, encontrar um método ideal para que pessoas surdas consigam escrever, seguindo as normas da Língua Portuguesa, tem suscitado incontáveis discussōes entre os estudiosos do ramo.

No decorrer do tempo, várias metodologias foram introduzidas no ensino dos alunos surdos, entre elas, o Oralismo, a Comunicação Total e o Bilinguismo. 
O método do Oralismo tinha com principal objetivo desenvolver a oralidade do surdo. De acordo com Goldfeld (2002), essa concepção de educação enquadra-se no modelo clínico, destacando a importância da integração dos surdos na comunidade de ouvintes. Para isso ocorrer, o sujeito surdo deveria aprender a falar por meio de reabilitação da fala em direção à "normalidade" exigida pela sociedade.

Mesmo após a constatação de que o Oralismo foi um fracasso e deixou muitas experiências negativas para o povo surdo, hoje ainda existem escolas especiais brasileiras que insistem em trabalhar com esse método. Essas escolas priorizam o desenvolvimento da oralidade e da audição, como se isso fosse um prérequisito para a alfabetização do sujeito surdo e sua inserção na sociedade.

No método da Comunicação Total permitia-se o uso de qualquer estratégia que pudesse resgatar a comunicação das pessoas surdas. Este modelo combinava a língua de sinais (LS), gestos, leitura labial, entre outros recursos que colaborassem com o desenvolvimento da língua oral. Esta metodologia, porém, não surtiu resultados satisfatórios, visto que a sua abordagem defendia o uso simultâneo das duas línguas: a oralização e os sinais, configurando-se o bimodalismo. Por serem duas línguas distintas e com estruturas sintáticas diferentes, a aprendizagem dos alunos ficava comprometida, pois não sabiam se deveriam prestar atenção nas mãos do sinalizante ou na boca. Isso significava que ao falar e sinalizar ao mesmo tempo resultava a produção de um 'português sinalizado' e não de Libras.

A Metodologia Bilíngue consiste em trabalhar com duas línguas no contexto escolar e, neste caso, as línguas em questão são a Língua Brasileira de Sinais (Libras) e a Língua Portuguesa (LP) na modalidade escrita.

O Decreto Federal No 5.626 de 22 de dezembro de 2005, que regulamenta a Lei No 10.436/2002 que, por sua vez, dispóe sobre a Libras, estabelece que os alunos surdos devem ter uma educação bilíngue, na qual a Libras deve ser considerada a primeira língua (doravante L1) e a LP, na modalidade escrita, a segunda língua (doravante L2). Conforme destaca Capovilla (2008, p.1540), a perspectiva do bilinguismo possibilita que a criança seja imersa no universo da língua de sinais e, a partir da LS, ocorra seu desenvolvimento linguístico e cognitivo. Tal imersão favorecerá, mais tarde, o desenvolvimento das habilidades de leitura e de escrita em LP.

Lacerda (1998), ao defender a Metodologia Bilíngue, ressalta que os surdos adquirem conhecimentos por meio do canal visual, e a mistura entre línguas utilizada na Comunicação Total dificulta a aquisição dos 
conhecimentos pelos surdos, pois cada língua tem características próprias e independentes, tornando-se assim impossível falar ambas as línguas (sinalizada e oral), ao mesmo tempo, no âmbito escolar.

Este trabalho enfatiza a necessidade de o surdo ser inserido em um ambiente favorável para a aquisição das duas línguas. Para tanto, faz-se necessário dispor de pessoas que tenham domínio de ambas as línguas, a Libras e a LP, no caso do Brasil. Os Centros de Atendimento Especializados na Área da Surdez (CAES) ${ }^{1}$ e as escolas especiais têm sido os espaços onde ocorre a estimulação da linguagem e a alfabetização das crianças surdas brasileiras.

De acordo com Fernandes (2007, p.2):

[...] embora brasileiras, as crianças surdas necessitam de uma modalidade linguística que atenda as suas necessidades visuais espaciais de aprendizagem, o que significa ter acesso à Libras, assim que for diagnosticada a surdez, para suprir as lacunas que a oralidade não preenche em seu processo de desenvolvimento da linguagem e conhecimento de mundo. Essa situação configura o bilinguismo dos surdos brasileiros: aprender a língua de sinais, como primeira língua, preferencialmente de zero a três anos, seguida do aprendizado do português, como segunda língua.

Há elementos usados na LP falada e escrita tais como: artigos, conjunções, preposições e, em alguns casos, certos tipos de verbos que não são sinalizados em Libras. Fernandes (2012, p.62) explica que:

[...] essas omissões que ocorrem na Libras em relação aos artigos, preposições e flexões verbais ou nominais (gênero, número) nos levam a pensar que a gramática da Libras seria mais "simplificada" em relação ao português, mas não se trata disso. Enquanto que no português há elementos conectivos indicados com palavras, na Libras esses mecanismos são discursivos e espaciais, estando incorporados ao movimento ou em referentes espaciais.

Entretanto, a maioria dos professores desconhece o fato de que o aluno surdo fala uma língua e precisa escrever em outra. E muitos professores que

\footnotetext{
${ }^{1}$ De acordo com a Resolução 002/2008, "CAES é um serviço de apoio pedagógico especializado, para alunos surdos, que funciona em estabelecimentos do ensino regular da Educação Básica, com oferta de Ensino Fundamental das redes: estadual, municipal e particular de ensino." (PARANÁ, 2008, p.01).
} 
trabalham com surdos incluídos nas salas de aula regulares não levam em consideração essa diferença linguística ao confrontar-se com um texto escrito pelo surdo.

Os professores bilíngues (fluentes em Libras e em Português), que trabalham com surdos em escolas especiais ou CAES, são conhecedores da história da educação dos surdos, bem como das metodologias e estratégias adequadas à aquisição dos conteúdos escolares. Porém, pode acontecer que uma parcela de professores que trabalham no ensino regular com alunos surdos incluídos, desconheçam essas práticas. Com isso, esses alunos, ao invés de se sentirem incluídos, acabam sendo excluídos do processo escolar e impossibilitados de adquirir, de forma efetiva, o conhecimento.

O Decreto No 5.626/2005, em seu Art. 14. \$ 1 ${ }^{\circ}$, Incisos VI e VII, garante aos alunos surdos que as avaliações devem ocorrer em ambas as línguas, Portuguesa/Libras, ao sugerir a adoção de "mecanismos de avaliação coerentes com o aprendizado de segunda língua, na correção das provas escritas, valorizando o aspecto semântico e reconhecendo a singularidade linguística manifestada no aspecto formal da Língua Portuguesa" (BRASIL, 2005, p.4-5).

Com base em suas experiências com crianças e jovens surdos e na convivência social com a comunidade surda, Duarte e Padilha (2012, p.316), quando tratam das dificuldades dos surdos em relação à LP, relatam que os surdos "questionam por que a escrita da LP no cotidiano é tão diferente dos livros pelos quais são alfabetizados na LS".

Isso ocorre pelo simples fato de que o ouvinte aprende, fundamentalmente, pelo canal auditivo, relacionando as palavras aos fonemas apresentados a ele. O surdo aprende por meio do canal visual e, portanto, precisa se apoiar na imagem da palavra, seu sinal e seu significado e não nos fonemas.

Santos (2011) propõe uma discussão acerca da aprendizagem da escrita da Língua Portuguesa por surdos. Ao comparar a alfabetização da criança surda com a criança ouvinte, explica que "a criança ouvinte, durante o período de contato com os sinais gráficos, passa por estágios de evolução, que são caracterizados em quatro grandes níveis: Pré-Silábico, Silábico, Silábico-Alfabético e Alfabético". Já em relação aos surdos, a autora enfatiza que "[...] a realização dessas etapas não gera resultados satisfatórios, pois elas estão voltadas, na maioria das vezes, para a correspondência entre som e grafia" (SANTOS, 2011, p.4).

De acordo com Salles (2002), “[...] o primeiro aspecto a considerar é que as línguas de sinais utilizam a modalidade visual espacial, que se distingue da modalidade oral auditiva, utilizada pelas línguas orais" (SALLES et al., 
2002, p.78). Muitas vezes, acredita-se que basta escrever uma palavra no papel para que o surdo entenda o que se está falando. Isso se deve ao fato de que as pessoas ouvintes aprendem ouvindo e associam o som ao objeto ou à coisa que se fala. A pessoa ouvinte também associa a palavra silabicamente à imagem, o que se aprende a fazer desde criança. $\mathrm{O}$ mesmo não acontece com o surdo, pois para este é como se tivesse em sua mente apenas a imagem das coisas que vê, buscando relacionar esta imagem ao sinal e às palavras para gerar sua escrita. Assim, não se obtém resultado satisfatório ao escrever uma palavra para o surdo, pois ele tem que associá-la a um sinal ou a uma imagem que conheça.

Ainda, todo vocabulário que um ouvinte adquiriu foi processado prioritariamente pelo canal auditivo. Porém, ao longo de todo esse processo, ocorreram, também, pistas visuais das quais ele teve a oportunidade de observar os usos e as funçóes em determinados objetos, além de ouvir seus nomes, com frequência. Ou seja, desde bebê, ele ouve seus pais, parentes, vizinhos, o rádio, a televisão entre outros. À medida que vai crescendo, consegue distinguir os significados das palavras e incorporar sinônimos, enriquecendo, assim, seu vocabulário no decorrer de toda sua vida. Ao escrever, o ouvinte, portanto, busca estas palavras e tenta ordená-las no papel.

Ao considerarmos que o sujeito surdo não assimila nada ou praticamente nada pelo canal auditivo, surge a seguinte questão: por onde é processado todo esse conhecimento para a aquisição de vocabulário? A única forma que o surdo tem para aprender as palavras é pelos olhos, mas os olhos não distinguem os sons. Como ele não conhece os sons das palavras, não sabe como pronunciá-las. As palavras que existem em sua mente são aquelas poucas que ele visualizou em sua forma escrita (se ele já foi alfabetizado).

Em outras palavras, para uma pessoa ouvinte ocorre mentalmente a "visualização" da palavra escrita e sua associação com o som que as sílabas isoladas e agora reunidas representam. Ao reler a palavra, imagina-se o som e seu significado. Se a pessoa entrar em contato com a palavra em outra ocasião, lendo-a novamente, ela fará a decodificação pela rápida e sequencial montagem silábica, mentalizará o som em seu inconsciente e associará a palavra ao que o "som mental" quer dizer.

Com o surdo não há essa associação, pois ele tenta associar o sinal a uma imagem. Essa transcodificação associativa palavra-som-significado não existe na mente da pessoa surda. Assim, como não há comunicação por meio da oralidade com os surdos, mas por meio de sinais visuais, ao sinalizar uma 
palavra que ele não está acostumado a usar e pedir para que a escreva, ele terá muita dificuldade (como erros de grafia) ou poderá não saber escrevê-la. Uma palavra escrita para o surdo nada mais é do que um simples desenho e ele não consegue associá-la a nenhum tipo de som pelo simples fato de nunca ter ouvido. Por isso, a ideia pré-concebida de que bastaria sinalizar uma palavra, letra por letra, por meio do alfabeto manual (datilológico) para que um surdo a compreenda é uma ilusão.

No processo de escrita o aluno surdo tenta buscar em seu "arquivo mental" imagens que se relacionam com o que está lendo, mas certamente não encontrará todas as imagens de que precisa. Boa parte daquelas que ele lembrar não mais saberá como escrevê-las, visto que o seu contato com aquela palavra pode não ter sido suficiente para registrá-la em sua mente, principalmente aqueles sinais com os quais não tem contato usual rotineiro, o que ocasiona textos curtos e bastante limitados. Fica fácil imaginarmos essa situação se fizermos a analogia de que o surdo não vê uma palavra, mas sim uma espécie de desenho, conforme explanado anteriormente.

O surdo também precisa ter acesso a todo o processo gramatical, estrutural e de concordância que a LP exige. Neste sentido, Santos (2011, p.2) afirma que:

[...] a tarefa de escrever é complexa e não se limita à simples aprendizagem dos códigos de uma língua. Exige do indivíduo tanto a potencialidade de assimilar as diferenças específicas dos sistemas fônico, fonológico, morfológico e lexical da língua, quanto a habilidade de identificar o que há de peculiar na estrutura sintática e no modo como as relaçôes semânticas se estabelecem.

O vocabulário que um ouvinte tem em palavras, o surdo tem em sinais, mas ainda não é possível escrever diariamente em sinais, pois o Sign Writing (Escrita em Sinais) ainda está em estudo. ${ }^{2}$

O surdo grava todas as imagens que vê, mas não as ouve, portanto, não sabe as denominações. Quando vai para a escola, não adianta apenas mostrar-lhe o sinal ou a escrita sem lhe apresentar o objeto correspondente e vice-versa. Portanto, não se obtém êxito somente escrevendo uma palavra

\footnotetext{
${ }^{2}$ Marianne Rossi Stumpf (surda) é uma pesquisadora brasileira que tem se dedicado à elaboração e divulgação da Escrita de Sinais. É Doutora em Informática na Educação, pela Universidade Federal Rio Grande do Sul, com a tese: Aprendizagem de Escrita de Lingua de Sinais pelo sistema Sign Writing: Linguas de Sinais no papel e no computador (2005).
} 
pois ele tem que associá-la a um sinal que conheça. Como pondera Perlin (2010, p.510), "a escrita do surdo não vai se aproximar da escrita do ouvinte". Diante desse contexto, cabe ao professor conhecer essa realidade e ter um olhar diferenciado ao avaliar a escrita do surdo. O Decreto No $5.626 / 2005$, conforme já mencionado, assegura este direito aos alunos surdos.

Para Lessa-de-Oliveira (2012), as crianças surdas podem levar até seis anos em média para serem alfabetizadas e, em muitos casos, essa alfabetização não é suficiente para elas aprenderem o português fluentemente. Os próprios surdos falam do seu sofrimento em aprender a ler e escrever em uma língua que não podem ouvir.

Os aspectos abordados anteriormente sobre a diferença no processo de escrita entre surdos e ouvintes também são discutidos por Perlin (2010). A autora explica a complexidade desse processo, que é sintetizada no seguinte relato:

É tão difícil escrever. Para fazê-lo, meu esforço tem de ser num clima de despender energias o suficiente demasiadas. Escrevo numa língua que não é minha. Na escola fiz todo esforço para entender o significado das palavras usando o dicionário. São palavras soltas elas continuam soltas. Quando se trata de pôlas no papel, de escrever meus pensamentos, elas são marcadas por um silêncio profundo. Eu preciso decodificar o meu pensamento visual com palavras em português que têm signos falados. Muito há que é difícil ser traduzido, pode ser apenas uma síntese aproximada. Tudo parece um silêncio quando se trata da escrita em português, uma tarefa difícil, dificílima. (PERLIN, 2010, p.57).

Stumpf (2008) questiona as práticas escolares no Brasil em relação aos surdos e propõe alguns aspectos importantes para que ocorra uma educação inclusiva pautada na ética, respeito e responsabilidade. Para isso, ressalta a importância de professores habilitados em Libras, intérpretes e professores surdos dentro das escolas regulares de ensino. Nesta perspectiva, ela afirma que:

O aluno surdo inserido no mesmo espaço educacional de alunos ouvintes, sem o suporte adequado, vai tentar seguir o modelo ou se comportar como um deles. Assim este aluno não conseguirá construir sua verdadeira identidade, pois não está em contato com seus pares surdos e nem com a sua língua de sinais. A língua de sinais aparece muito pouco e sobre a cultura surda, não há sinais. Como esse aluno vai ter acesso ao conhecimento? (STUMPF, 2008, p.25). 
A autora salienta ainda que o que acontece na prática está aquém de atender a essas indicações, pois as dinâmicas educativas na sala de aula estão focalizadas na língua oral e na escrita da mesma e os alunos surdos e ouvintes são avaliados por meio dos mesmos critérios, não respeitando, desta forma, a diferença linguística do surdo assegurada no Decreto No 5.626/2005.

O documento denominado "Política Nacional de Educação Especial na Perspectiva da Educação Inclusiva (2008)" preconiza que o aluno surdo seja inserido nas salas comuns de ensino e os conteúdos sejam ministrados em LP e Libras com a mediação do tradutor/intérprete de Libras. E, no contraturno, o aluno surdo deve receber Atendimento Educacional Especializado (AEE).

Contudo, a garantia da presença de tradutores/intérpretes de Libras em salas comuns de ensino não é sinônimo de inclusão. Em primeiro lugar, porque há muitos surdos, filhos de pais ouvintes, que não dominam a Libras, e a figura do tradutor/intérprete nada significaria para a sua escolarização. "O intérprete perde a função de traduzir os conteúdos do português oral para a Libras, já que os alunos não possuem nem uma nem outra língua” (GARCÊZ, 2011, p.11).

Em segundo lugar, não se pode chamar uma escola de 'inclusiva' apenas por ter um intérprete de língua de sinais presente na sala de aula. Não basta que apenas um indivíduo dentro de uma organização escolar saiba comunicar-se com surdos. O intérprete não está 'colado' ou 'suturado' ao surdo nem na sala de aula. Por alguns momentos, certamente, ele precisará ausentar-se. Então, como ficam as necessidades comunicativas dos surdos?

De acordo com Resende (2011, p.1):

A língua de instrução utilizada em todos os espaços escolares da escola inclusiva é o português. No máximo, os alunos contam com a presença de intérpretes de língua de sinais durante as aulas, o que muitas vezes torna inviável o ensino já que a criança surda nem sequer domina Libras e muito menos possui conhecimento prévio de mundo por meio de língua nenhuma. Mas a metodologia de ensino continua sendo a mesma para surdos e ouvintes. $\mathrm{O}$ português é ensinado como primeira língua aos surdos descumprindo a legislação.

Por isso, a comunidade surda é contrária à política de inclusão e argumenta que colocar crianças surdas, oriundas de famílias ouvintes, que não tiveram acesso a Libras, junto com alunos ouvintes, mesmo com a mediação do tradutor/intérprete, não traz resultados satisfatórios em relação a sua aprendizagem. Segundo representantes dessa comunidade, as salas 
de aula comuns não são o espaço ideal para a criança surda adquirir sua língua natural de forma espontânea, como ocorre com as crianças ouvintes (RESENDE, 2011).

Portanto, sob o ponto de vista das pessoas surdas, o ideal é investir em escolas bilíngues, onde as crianças surdas podem ter acesso à Libras desde a mais tenra idade, por meio do contato com seus pares e com estratégias metodológicas de ensino que atendam as suas particularidades.

Nesta perspectiva, um grupo de pesquisadores surdos e ouvintes, após muitos debates, elaborou um Relatório contendo subsídios para a política linguística de educação bilíngue, publicado pelo MEC/SECADI em 2014, em que o principal objetivo é propagar e assegurar que a escolarização dos surdos no Brasil seja realizada em escolas bilíngues.

A Educação Bilíngue de surdos envolve a criação de ambientes linguísticos para a aquisição da Libras como primeira língua (L1) por crianças surdas, no tempo de desenvolvimento linguístico esperado e similar ao das crianças ouvintes, e a aquisição do português como segunda língua (L2). A Educação Bilíngue é regular, em Libras, integra as línguas envolvidas em seu currículo e não faz parte do atendimento educacional especializado. O objetivo é garantir a aquisição e a aprendizagem das línguas envolvidas como condição necessária à educação do surdo, construindo sua identidade linguística e cultural em Libras e concluir a educação básica em situação de igualdade com as crianças ouvintes e falantes do português (BRASIL, 2014, p.6).

Diante disso, alguns municípios têm lutado para implantar escolas bilíngues e as cidades menores estão tentando criar polos centralizados para atender também os surdos das cidades vizinhas. Conforme o documento: "Os municípios que não comportem escolas bilíngues de surdos devem garantir educação bilíngue em classes bilíngues nas escolas comuns (que não são escolas bilíngues de surdos).” (BRASIL, 2014, p.4).

Para entendermos a estruturação da escrita produzida pelos alunos surdos, suas dificuldades e seu modo singular de compreender a LP e expressá-la, por meio da escrita, apresentamos o texto abaixo, escrito por uma pessoa ouvinte, que tenta escrever em uma língua que não é a sua língua nativa. Trata-se de um e-mail que foi enviado por um norte-americano (ouvinte) à sua cunhada brasileira:

Eu carro vende para $\$ 1600.00$ ou posso para um pouco menos se preciso talvez $\$ 1500$ um pouco menos para familia. Eu gosto esse computador muinto, eu compra uma pra me tambem and e otimo!! Que voces pensa com esse notebook? Pode vende para esse 
preso? Sabe alguma pessoa intersante? Escreve para me por favor... tambem tem outro cam para computador paricedo do que o cam eu compra para Adriano....quanto voces pense eu possa venda pra? Um abraso para todo mundo... Ron. (FERNANDES, 2007, p.9).

Ao ler este e-mail pode-se identificar uma singularidade: por ser americano e falante da língua inglesa ele está tentando escrever em uma língua que não é a sua. A língua 1 (L1) de Ron é o inglês, e ele escreveu o e-mail utilizando a sua língua 2 (L2) - o português. A pessoa que não domina o inglês e tenta produzir um texto, certamente, escreverá com vestígios da sua L1 no texto: a estrutura, um vocabulário etc., conforme fez Ron em seu texto.

Com o surdo, portanto, não é diferente. Ele fala uma língua e escreve em outra. Quando se trata de língua é importante lembrar que os surdos são praticamente estrangeiros em seu próprio país. Por isso, ao inserir-se em um meio escolar, ele encontra inúmeras dificuldades, tanto socialmente como em relação aos conteúdos.

Em relação à complexidade que envolve o desenvolvimento da escrita pelas pessoas surdas, alinhamo-nos a Santos (2011, p.2-3) quando enfatiza que "alguns discursos tentam relacionar a frequência dessas dificuldades a uma natureza patológica, entendendo a surdez como deficiência e rotulando, negativamente, a escrita do surdo".

A autora argumenta que "no âmbito dos estudos surdos, surdez não é sinônimo de doença/deficiência, mas de diferença”" (SANTOS, 2011, p.2-3).

Portanto, as diferenças existentes no processo de desenvolvimento da escrita pelos surdos não podem ser associadas à surdez, mas às línguas envolvidas nesta dinâmica, constituindo-se, pois, em casos de bilinguismo Libras-Português, tal como é o caso de nosso estudo. Portanto, cabe à instituição de ensino e às práticas realizadas nela, um trabalho que permita o desenvolvimento pleno deste processo, sem marginalizar, reprimir, isolar ou omitir.

\section{ASPECTOS METODOLÓGICOS}

Diante das consideraçôes apresentadas, o nosso estudo pretende analisar textos escritos por alunos surdos, que frequentaram o ensino fundamental de uma escola pública do interior do Paraná, alfabetizados por meio de uma metodologia bilíngue.

Esta pesquisa possui uma abordagem predominantemente qualitativa, pois foram considerados aspectos de subjetividade dos participantes, 
fornecidas por eles, por meio da expressão escrita, em situação de interação. Quanto ao tipo, classificamos o estudo como descritivo de caráter exploratório (MARCONI et al. , 1996).

Participaram do estudo alunos surdos, que iniciaram atendimento educacional no CAES, com idades por volta de dois e quatro anos. Para a identificação dos estudantes, serão usadas as letras 'L', 'R', 'R1', 'E' e 'V' para preservar suas identidades. A turma era composta por sete alunos da mesma faixa etária e com surdez profunda bilateral. Assim que ingressaram no CAES, suas famílias, pais, irmãos e amigos começaram a participar dos cursos em Libras oferecidos pela mesma professora que realizava a estimulação da linguagem dos surdos no CAES. Esse fato é muito importante, pois alunos surdos, filhos de pais ouvintes, devem ser inseridos em CAES ou escolas bilíngues assim que a surdez for diagnosticada, a fim de adquirirem a LS, já que sem uma língua torna-se impossível qualquer criança aprender a ler ou escrever.

No momento desses alunos ingressarem no ensino fundamental (ainda na modalidade seriada antiga de 8 anos) de $1^{\text {a a }} 4^{\mathrm{a}}$ série, criou-se um programa chamado "Programa de Escolarização Regular com Atendimento Especializado (PERAE)". Esse programa permite que os alunos surdos fiquem em uma sala, separados dos demais alunos ouvintes. Eles são alfabetizados e todo conteúdo é transmitido em LS, que é considerada a língua natural das pessoas surdas.

A metodologia utilizada com esses alunos, durante toda escolarização, foi a Bilíngue, ou seja, a Libras e a LP (escrita). Ao ingressarem na 5a série, os alunos foram acompanhados por uma tradutora/intérprete de Libras.

A coleta de dados foi realizada diretamente com a professora do CAES, que também atuava como intérprete desses alunos. Todos os textos foram escolhidos seguindo os seguintes critérios: textos produzidos a partir de uma história ou documentário narrado em Libras; escrever sobre o colega; a partir de um filme; texto com temas livres e texto produzido em grupo a partir de um tema. Foram analisados cinco textos, sendo que o último apresenta a visão dos próprios surdos em relação ao processo de inclusão do qual fizeram parte.

A interpretação das análises dos textos foi realizada com respaldo nos seguintes autores: Fernandes (2007), Guarinello, Massi e Berberian (2007), Santos (2011), Duarte e Padilha (2012). Esses são alguns pesquisadores que têm se debruçado em pesquisas que tem como foco a aquisição da escrita dos surdos.

Em relação aos critérios utilizados para as análises dos textos, salienta-se que, apesar de destacarmos algumas trocas morfológicas, sintáticas e outras, nosso foco 
não está em apontar o suposto "erro" do aluno, mas em compreender a relação que ele consegue fazer entre a LS e a LP, visto que são línguas de modalidades diferentes. Adota-se, portanto, uma abordagem interlinguística de análise (LIMA-SALLES \& VIANA, 2010), ao apontar elementos relacionados à inexistência ou inadequação de concordância nominal (gênero, pessoa e número), acentuação, troca ou omissão de artigos, pontuação entre outros aspectos.

Os textos tomados para análise foram escritos entre os anos 2003 e 2011 quando os alunos frequentavam as seguintes séries: $2^{\mathrm{a}}, 4^{\mathrm{a}}, 6^{\mathrm{a}}$ do ensino fundamental e $2^{\circ}$ ano do ensino médio.

\section{DISCUSSÃO DOS DADOS}

Após apresentarmos algumas premissas do estudo em tela, bem como da metodologia adotada, passamos à discussão dos dados. A produção do texto I, a seguir, foi realizada da seguinte forma: os alunos, em dupla, deveriam entrevistar um ao outro e depois escrever sobre o colega.

Texto I: produzido pelo aluno "R" oito anos de idade, em junho de 2003, quando cursava a 2a série. Ele escreveu sobre o seu colega Lúcio. ${ }^{3}$

\begin{tabular}{|c|c|}
\hline TEXTO ORIGINAL & $\begin{array}{l}\text { TEXTO DIGITADO COM LINHAS } \\
\text { NUMERADAS }\end{array}$ \\
\hline A inteligente e gasta estudor. de meu camigo & $\begin{array}{l}\text { 1. Lúcio } \\
\text { 2. O Lúcio tem cavalo, cachorro } \\
\text { 3. O Lúcio é inteligente e gosta estudar. Ele } \\
\text { meu } \\
\text { 4. amigo muito Lúcio. } \\
\text { 5. O Lúcio tem irmão Luis. Lúcio tem bebê } \\
\text { 6. Manuele. } \\
\text { 7. O Lúcio vem onibis. O Lúcio tem papai, } \\
\text { mamãe. }\end{array}$ \\
\hline
\end{tabular}

FIGURA 1 - Texto I - Aluno "R" escreve sobre "Lúcio" em 2003.

Fonte: Elaborado pelas autoras.

\footnotetext{
${ }^{3}$ Nome fictício. Os nomes utilizados em seu texto foram ocultados e na transcrição trocados por outros com a finalidade de preservar sua identidade, conforme já acima explicado.
} 
Ao analisar o texto, é possível observar que, embora o texto seja curto, o autor conseguiu escrever muitas coisas a respeito do seu colega. Na maioria das frases, ele repetiu o nome "Lúcio", talvez por ainda não dominar o uso de pronomes. Na frase: "Ele meu amigo muito Lúcio" (linhas 3 e 4), usou o pronome pessoal "Ele", mas ao final da frase repetiu o nome "Lúcio". Na mesma frase o "muito" indica "grande amigo", isto foi explicado pelo aluno (autor do texto) à sua professora.

Ele demonstrou domínio no uso dos substantivos próprios e noções de pontuação. Fez uso da conjunção "e" (linha 3), o que demonstra que ele já consegue fazer a relação da Libras com o português escrito; há palavras sem ortografia, apenas, na palavra "ônibus", este a escreve "onibis" (linha 7).

A frase: "O Lúcio vem onibis", (linha 7), parece estar incompleta, mas o fato de os alunos estarem na escola subentende-se que o Lúcio vem "à escola" de ônibus; "Lúcio tem bebê Manuele" (linha 6) refere-se à irmã do aluno, cujos elementos contextuais só podem ser conhecidos devido à interação com o aluno surdo.

Podemos afirmar que o processo de escrita tinha para os alunos surdos um verdadeiro significado, visto que este era desenvolvido de maneira contextualizada e os alunos podiam explicar, em sinais, o que escreviam quando questionados pela professora. Tal experiência vai ao encontro do que postula Santos (2011, p.14) quando afirma que "nos anos iniciais da escolarização, boa parte das crianças, sejam elas surdas ou ouvintes, são expostas a atividades artificiais de escrita em sala de aula”.

Também, Guarinello, Massi e Berberian (2007, p.207) destacam que "a língua muitas vezes é ensinada por meio de atividades mecânicas e repetitivas, como se fosse um código pronto e acabado". Ainda sobre esta questão, Duarte e Padilha (2012, p.311) destacam que "aprender uma língua através de suas unidades básicas, de forma estanque e descontextualizada, não leva a um aprendizado satisfatório, ou mesmo leva ao fracasso, em termos escolares".

É neste sentido que insistimos que o texto escrito pelo próprio surdo é a melhor forma de verificar seu aprendizado da LP. Tal tarefa pode servir para mudar discursos veiculados por parte dos professores que trabalham com os surdos, já que muitos afirmam que os surdos são excelentes copistas. Duarte e Padilha (2012, p.317) afirmam que "apreender uma língua escrita sem apreender as estruturas da língua, gera, no meio escolar, na maioria das vezes, não uma produção escrita em LP, mas apenas imitação, apenas cópia”. 
Para que o aluno surdo consiga chegar à fase de elaborar seu próprio texto, com suas opinióes e autonomia, é primordial que ele já tenha mergulhado no universo da LS, sua língua materna. Assim, mesmo não sabendo a escrita das palavras, tem o vocabulário em sinais e, com auxílio do professor, consegue colocar suas ideias no papel. Essa perspectiva será discutida ao analisarmos o texto II, a seguir.

Texto II: produzido pelo aluno "R1", aos dez anos de idade, quando cursava a $4^{\text {a }}$ série, em maio/2005.

\begin{tabular}{|c|c|}
\hline 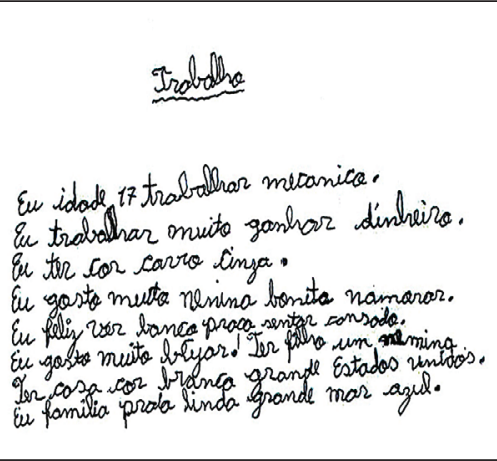 & $\begin{array}{l}\text { 1. Trabalho } \\
\text { 2. Eu idade } 17 \text { trabalhar mecanico. } \\
\text { 3. Eu trabalhar muito ganhar dinheiro. } \\
\text { 4. Eu ter cor carro cinza. } \\
\text { 5. Eu gosto muito nenina bonita namorar. } \\
\text { 6. Eu feliz ver banco praça sentar cansado. } \\
\text { 7. Eu gosto muito beijar! Ter filho um nemina } \\
\text { 8. Ter casa cor branca grande Estados Unidos. } \\
\text { 9. Eu família praia linda grande mar azul. }\end{array}$ \\
\hline
\end{tabular}

FIGURA 2 - Texto II - Produzido pelo aluno "R1" em 2005. Fonte: Elaborado pelas autoras.

Esta produção foi realizada com base em uma discussão a respeito dos sonhos dos alunos para o futuro. $\mathrm{O}$ aluno demonstra que pretende morar em uma casa branca como a da sede do governo dos Estados Unidos da América - EUA (linha 8). Isto porque em uma das aulas foram levados vários cartôes postais, fotografias e documentários para explicar o episódio do World Trade Center. A partir disso, este aluno passou a ter uma profunda admiração pelos EUA. É importante ressaltar que, além da catástrofe de 11 de setembro de 2001, os alunos viram também fotos, postais e reportagens sobre alguns pontos turísticos. A curiosidade do aluno em relação aos EUA era tamanha que todos os dias ele perguntava algo sobre esse país.

Percebe-se que não há flexão de tempo verbal na maioria das frases. Isto porque na Libras o tempo é expresso por meio de relações espaciais: passado para trás, futuro - para frente e presente - no espaço imediatamente à frente 
do corpo do locutor, conforme pode ser verificado na representação abaixo: ${ }^{4}$

\begin{tabular}{|l|l|l|}
\hline PASSADO & FUTURO & PRESENTE (HOJE) \\
\hline
\end{tabular}

FIGURA 3 - Representação do tempo em Libras.

Fonte: STREIECHEN, 2013.

A ausência de flexão verbal é um dos elementos que se sobressai na escrita deste texto, causa da influência da LS sobre a LP. Na linha 2, o aluno escreve "mecanico" sem o acento. A acentuação é um aspecto da LP que depende da tonicidade e, como os surdos não pronunciam as palavras, é comum que também apresentem dificuldades em relação à acentuação.

Apesar de a pontuação também se apresentar como um aspecto que dificulta a escrita dos surdos, por estar diretamente vinculado à oralidade (entonação, ritmo, fluxo da fala etc.) (FERNANDES, 2007), o aluno fez uso da frase exclamativa (linha 7): "Eu gosto muito beijar!" Nas demais frases ele usou o ponto final.

Na linha 6, ao escrever: "Eu feliz ver banco praça sentar cansado", ele explica à professora e aos colegas que, quando estiver namorando, vai passear com sua namorada em uma praça. Neste caso, a frase só pode ser corretamente compreendida quando o aluno a contextualiza.

$\mathrm{Na}$ sequência, o aluno produz a palavra "menina" como "nenina" (linha 5 ) e nemina (linha 7). Isto ocorre porque os alunos visualizam a palavra globalmente sem o recurso da fala para frisar os fonemas conforme os ouvintes fazem ao escrever alguma palavra complexa.

Ainda na linha 7, na expressão: "Ter filho um nemina" ele realiza a concordância entre "filho" e "um", porém, esta não se estabelece com o

\footnotetext{
${ }^{4}$ As ilustraçôes deste trabalho foram realizadas por Sérgio Streiechen e fazem parte do livro LIBRAS: aprender está em suas mãos (STREIECHEN, E.M., 2013).
} 
segmento seguinte "nemina". Entretanto, este fato não deixa de evidenciar que, neste caso, o que está em jogo é que ele quer ter uma filha. Fernandes (2007) explica que a ausência de desinência para gênero e número em Libras é um aspecto evidente da interferência dessa língua na escrita, e a concordância nominal inadequada é uma constante nas construçóes escritas dos alunos surdos.

Desta forma, verifica-se que, apesar das dificuldades em relação à LP, o sujeito surdo é capaz de expressar suas opiniōes, ideias e desejos por meio da escrita. Para isso, há todo um trabalho importante que precisa ser realizado anteriormente, como a estimulação da linguagem, a Libras, neste caso, desde muito pequenos. Não há possibilidade de uma criança obter êxito em sua alfabetização se chegar à escola sem uma língua para se comunicar.

Dando continuidade ao processo de análise de produçôes escritas, a seguir, é analisado um texto decorrente de debate baseado em relatos de um acidente aéreo.

Texto III: produzido pelo aluno " $\mathrm{R}$ ", aos doze anos de idade, quando cursava a 6a série, no ano de 2007.

\begin{tabular}{|c|c|}
\hline 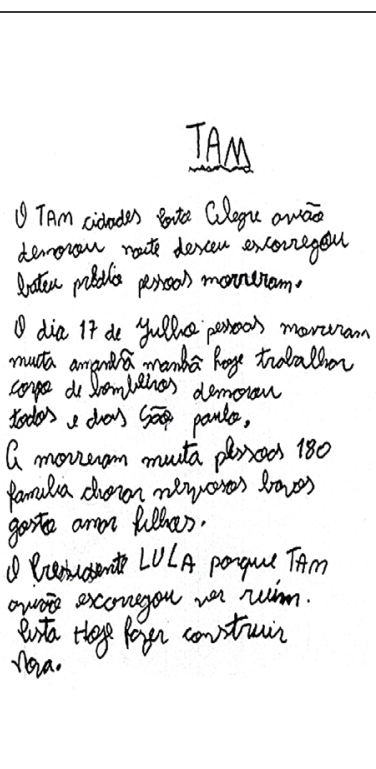 & $\begin{array}{l}\text { 1. TAM } \\
\text { 2. O Tam cidades Porto Alegre avião } \\
\text { 3. demorou noite desceu escorregou } \\
\text { 4. bateu prédio pessoas morreram. } \\
\text { 5. O dia } 17 \text { de Julho pessoas morreram. } \\
\text { 6. muita amanhã manhã hoje trabalhar } \\
\text { 7. corpo de bombeiros demorou } \\
\text { 8. todos e dias São paulo. } \\
\text { 9. A morreram muita pessoas } 180 \\
\text { 10. família chorar nervosos bavos } \\
\text { 11. gosto amor filhos. } \\
\text { 12. O presidente LULA porque TAM } \\
\text { 13. aviäo escorregou ver ruim. } \\
\text { 14. Pista hoje fazer construir } \\
\text { 15. nova. }\end{array}$ \\
\hline
\end{tabular}

FIGURA 4 - Texto III - Produzido pelo aluno "R” em 2007.

Fonte: Elaborado pelas autoras. 
Antes de os alunos iniciarem a produção desse texto, a professora promoveu um debate a respeito do que havia acontecido nos dias anteriores em relação ao acidente da TAM no aeroporto de Congonhas em São Paulo (2007). Assim, cada aluno expressava sua opinião sobre a tragédia. A professora registrava no quadro alguns vocábulos que surgiam na discussão e depois sinalizava um por um juntamente com os alunos. Ela sabia que, na hora da elaboração da escrita, os alunos poderiam usar estes vocábulos em seus textos. A maioria dos fatos narrados no texto em questão teve base nas discussões realizadas pelo grupo anteriormente.

O aluno cita as cidades envolvidas no acidente, "Porto Alegre" (linha 2), cidade de onde o avião partiu; "São Paulo" (linha 8) onde ocorreu o acidente. Os nomes das duas cidades estavam escritos no quadro. Diante disso, observa-se que os vocábulos, em LP, disponibilizados pela professora ao escrevê-los no quadro, passaram a ter um significado para o aluno, visto que ele consegue utilizar-se dessas palavras, contextualizá-las e escrevê-las em seu texto. Desta forma, observa-se que a professora se utiliza da metodologia Bilíngue - Libras e LP (escrita) em tempo integral nas suas aulas.

$\mathrm{Na}$ tentativa de expressar a demora dos bombeiros em concluírem o trabalho, o aluno recorre a vários advérbios "amanhã manhã hoje" (linha 6). Em Libras, essa demora que o aluno pretendia descrever poderia ser sinalizada com o sinal de "demorar", porém a intensidade 'demorar muito' é marcada pela expressão facial negativa (olhos e boca serrados), conforme a figura abaixo:

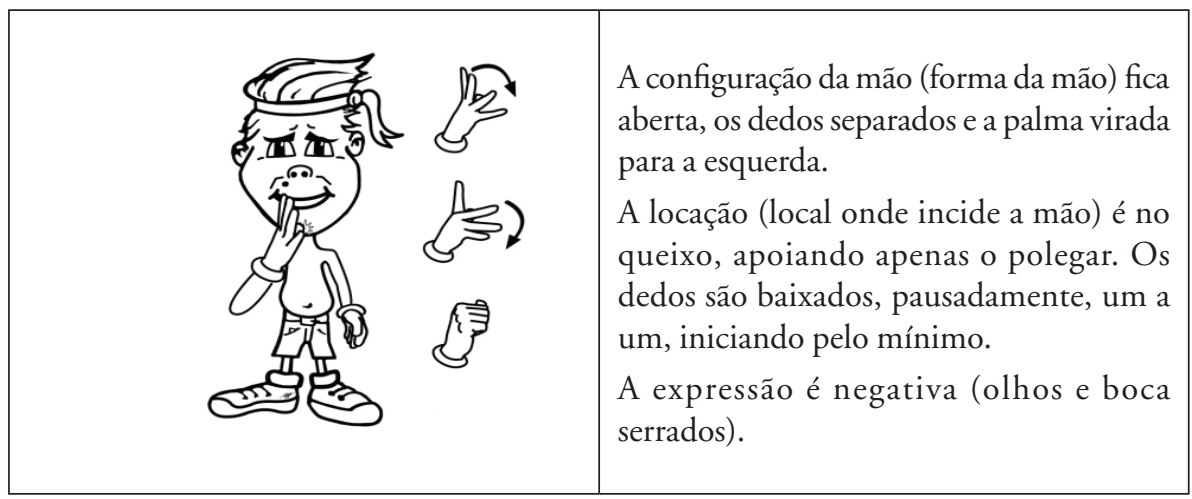

FIGURA 5 : Representação facial negativa em Libras.

Fonte: STREIECHEN, 2013. 
Supõe-se que, o fato de o aluno não conseguir encontrar uma palavra para descrever a intensidade que ele costuma utilizar na LS, por meio da expressão facial, ele decide escrever vários advérbios: "amanhã manhã hoje".

Nota-se que esse aluno tem noçôes de artigos e faz tentativas de seu uso: "O TAM" (linha 2), troca o "a" por "o"; "todos e dias São paulo" (linha 8), certamente pretendia usar "os", mas trocou por "e". Conforme já explicado, na LS não há o uso de artigos e conectivos. Fernandes (2007) destaca que o emprego destes elementos é extremamente difícil para os surdos, por isso o uso inadequado e a ausência destes é um aspecto comum nas produçôes dos surdos.

Apesar de o aluno ter usado artigo antes do verbo "morreram" (linha 9), ele conseguiu conjugar vários verbos, o que é raro na escrita de pessoas surdas, pois, normalmente escrevem os verbos no infinitivo. Em Libras, os sinais dos verbos permanecem sempre iguais independentemente do tempo e pessoa.

É muito comum professores que trabalham com surdos escreverem os verbos da mesma forma que os surdos, no infinitivo. Isto lhe tira a oportunidade de aprender que os verbos passam por modificaçôes, de acordo com o tempo da oração.

$\mathrm{Na}$ frase "família chorar nervosos bavos" (linha 10), o aluno inicia a frase no singular, entretanto os termos "nervosos" e "bravos" concordam entre si, utilizando-se da premissa de que o vocábulo família pode ser considerado um termo coletivo. Já em "bravos" (linha 10), omite a letra "r". Ao concluir o texto, utiliza outro elemento contextual dado como pista pela professora: depois do acidente a pista estava sendo consertada, prevalecendo, neste excerto, os verbos no infinitivo.

Em relação à palavra "bavos" - "bravos", salienta-se que a omissão ou troca de letras é algo constante na escrita de alunos surdos. Portanto, é importante entender que, se o aluno surdo nunca teve contato visual com determinado vocábulo escrito, ou o visualizou poucas vezes, na hora de escrever, ele possivelmente não se lembrará da ordem correta das letras ou fonemas em uma palavra. Observa-se, no entanto, que este aluno demonstra consistência de ideias e certo domínio no que se refere à gramática da LP, principalmente nos níveis morfológicos e sintáticos.

Ressalta-se que as ideias do surdo são elaboradas em Libras, mas na hora de escrever ele precisa usar a ordem da LP e, conforme apresentado nos exemplos acima, a Libras e a LP obedecem a estruturas sintáticas diferentes, 
o que causa a interferência de uma sobre a outra no processo de escrita, prevalecendo o conhecimento da língua primeira do surdo.

No texto a ser analisado a seguir, a produção foi baseada em um vídeo assistido pelos alunos.

Texto IV: produzido pelo aluno "R1", aos doze anos, quando cursava a $6^{\mathrm{a}}$ série, no ano de 2007.

\begin{tabular}{|c|c|}
\hline 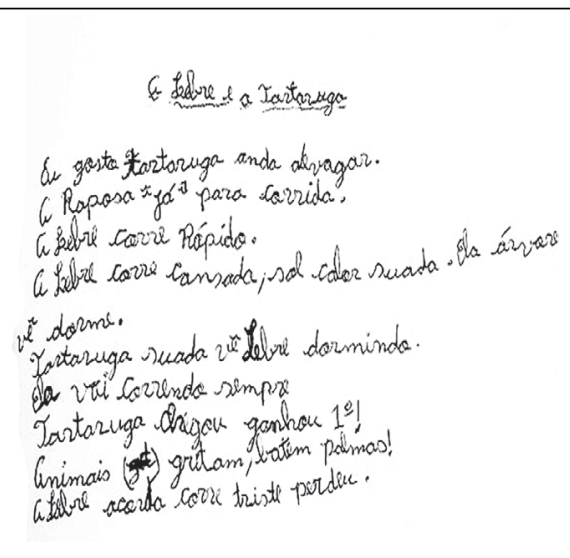 & $\begin{array}{l}\text { 1. A Lebre e a Tartaruga } \\
\text { 2. Eu gosto Tartaruga anda devagar. } \\
\text { 3. A Raposa "já" para corrida. } \\
\text { 4. A Lebre corre Rápido. } \\
\text { 5. A Lebre corre cansada, sol calor suada. Ela } \\
\text { 6. árvore vê dorme. } \\
\text { 7. Tartaruga suada vê Lebre dormindo. } \\
\text { 8. Ela vai correndo sempre. } \\
\text { 9. Tartaruga chegou ganhou 1"! } \\
\text { 10. Animais (...) gritam, batem palmas! } \\
\text { 11. A Lebre acorda corre triste perdeu. }\end{array}$ \\
\hline
\end{tabular}

FIGURA 6 - Texto IV: Produzido pelo aluno "R1”, em 2007. Fonte: STREIECHEN, 2013.

Nesse texto foi utilizada a seguinte técnica: os alunos assistiram, em LS, ao vídeo: "A Lebre e a Tartaruga". No decorrer da discussão a professora registrava o nome dos personagens da história no quadro. Os alunos contaram a história e fizeram a dramatização. Em seguida, desenharam os personagens e elaboraram o texto.

Ao analisar o texto, pode-se observar que o aluno descreveu apenas as partes que julgou mais importantes da história e, certamente, as que ele lembrou. Esse aluno demonstrou, em sua escrita, certo domínio no uso da pontuação, pronomes, conjugação verbal, concordância entre outros elementos. Não deixou de colocar a sua opinião em relação à sua preferência pela tartaruga - "Eu gosto Tartaruga" (linha 2). Na linha 3, ele escreve "já" colocando entre aspas para indicar a hora em que a raposa (juiz) abaixa a mão para dar início à corrida.

Apesar da dificuldade que os surdos apresentam na conjugação verbal, observa-se que o aluno conseguiu conjugar alguns verbos. A conjugação 
verbal faz parte da gramática da LP, e, embora seja uma flexão da mesma palavra, para o surdo torna-se uma dificuldade conjugar os verbos em seus textos.

Em LP sabemos que a noção de tempo é incorporada aos verbos por meio das conjugaçôes. Quando se diz: "estudo", "estudei", "estudarei" não é preciso destacar o tempo, pois as terminaçōes (sufixos) "o" "ei" e "arei" identificam o tempo: presente, passado, futuro, respectivamente.

Já em Libras, os sinais dos verbos permanecem sempre iguais, independentemente do tempo. O que determinará a marcação de tempo é um sinal auxiliar de advérbio que acompanha o verbo. Por exemplo, quando o surdo quer colocar o verbo ESTUDAR no presente, passado, ou futuro, respectivamente, ele sinaliza da seguinte forma: EU ESTUDAR AGORA (Eu estudo); EU ESTUDAR PASSADO (Eu estudei); EU ESTUDAR FUTURO (Eu estudarei).

Portanto, os sinais dos verbos não recebem afixos anexados à raiz como na LP. Por isso, a maioria dos surdos escreve praticamente todos os verbos no infinito. Por exemplo: "ESTUDAR" é um verbo que, na Libras, não apresenta concordância, visto que o sinal é sempre o mesmo independentemente de tempo, número e pessoa do verbo. Conforme apontam Duarte e Padilha (2012, p.318), “[...] na Língua de Sinais não há desinências verbais como na LP. Entendemos que o surdo precisa 'ver' para aprender a reconhecer e incorporar a estrutura verbal em sua materialização linguística”.

Em relação à acentuação, como exposto acima, é um aspecto que depende da tonicidade, e, para os surdos é extremamente difícil pelo fato desta exigir a consciência sonora das palavras. Ainda assim, o aluno acentua corretamente as palavras: "já" (linha 3), rápido (linha 4), "árvore" e "vê" (linha 6). Talvez por serem vocábulos simples e básicos, é possível que ele já tenha tido contato suficiente para registrá-lo em sua mente.

Observa-se, assim, que a metodologia bilíngue é a oportunidade de o aluno surdo ter acesso aos conteúdos, tanto por meio da sua língua materna - a Libras, quanto por meio da LP. Desta forma, esses sujeitos não se sentem excluídos do processo de ensino aprendizagem como tantos outros surdos têm se sentido no contexto inclusivo, onde prevalece apenas a língua majoritária da sociedade brasileira, a LP. Observemos, a seguir, o texto V, produzido a partir da discussão de um filme. 
Texto V: produzido pelo aluno "E", aos doze anos de idade, quando cursava a $6^{\mathrm{a}}$ série, no ano de 2007.

\begin{tabular}{|c|c|}
\hline 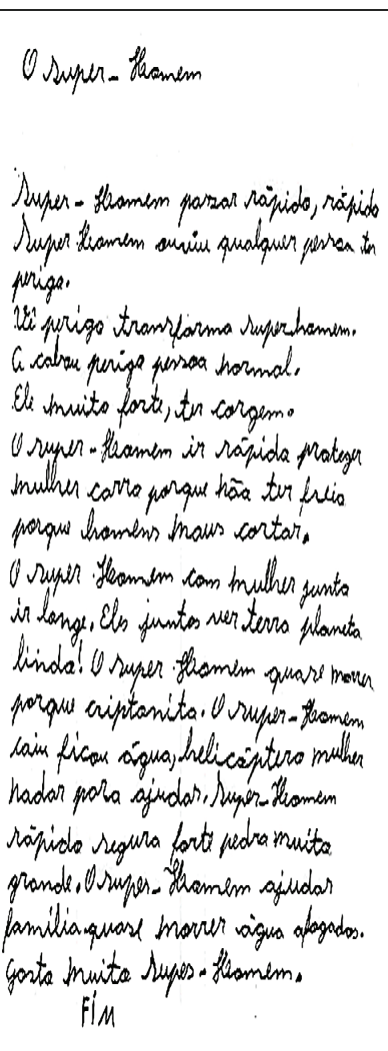 & $\begin{array}{l}\text { 1. O Super-Homem } \\
\text { 2. Super-Homem passar rápido, rápido } \\
\text { 3. Super-Homem ouviu qualquer pessoa ter } \\
\text { perigo. } \\
\text { 4. Vêperigo transformar Super-homem. } \\
\text { 5. A cabou perigo pessoa normal. } \\
\text { 6. Ele muito forte, ter corgem. } \\
\text { 7. O Super-Homem ir rápido proteger } \\
\text { 8. Mulher carro porque näo ter freio } \\
\text { 9. Porque homens maus cortar. } \\
\text { 10. O Super Homem com mulher junto } \\
\text { 11. Ir longe. Eles juntos ver terra planeta } \\
\text { 12. Lindo! O Super Homem quase morrer } \\
\text { 13. porque criptonita. O Super-Homem } \\
\text { 14. caiu ficou água, helicóptero mulher } \\
\text { 15. nadar para ajudar, Super-Homem } \\
\text { 16. rápido segura forte pedra muito } \\
\text { 17. grande. O Super-Homem ajudar } \\
\text { 18. família quase morrer água afogados. } \\
\text { 19. Gosto muito Supes-Homem. } \\
\text { 20 Fim }\end{array}$ \\
\hline
\end{tabular}

FIGURA 7 - Texto V: Produzido pelo aluno "E” em 2007. Fonte: Elaborado pelas autoras.

O principal objetivo dessa aula era o de que os alunos conseguissem fazer a leitura do poema os "Super-Heróis". Primeiramente, assistiram ao filme "O Super-Homem”. Depois de um longo debate sobre as cenas do filme, os alunos lembraram outros super-heróis que conheciam. Os nomes foram registrados no quadro pela professora, assim como toda parte lexical que surgia durante a conversação.

A professora, de forma contextualizada, fazia vários questionamentos a respeito dos super-heróis, por exemplo: "Os super-heróis sentem medo? Dor? Vergonha? Eles sofrem? Morrem? Alimentam-se? Têm famílias? Namorados 
(as)?” E assim por diante. Ela sempre registrava no quadro e explicava o significado das palavras e expressões que surgiam nos questionamentos e, consequentemente, encontrariam no poema. Quem já assistiu ao filme Superman: o retorno, dirigido por Bryan Singer em 2006, possivelmente consiga identificar algumas cenas da história no texto deste aluno e também perceber que o aluno destacou as partes que mais lhe impressionaram, com uma sequência lógica e coerente.

A maioria dos verbos foi escrita no infinitivo, tais como: "passar" (linha 2); "ter" (linha 3, 6 e 8); "ir" (linha 7); "cortar" (linha 9). A questão da flexão verbal, tal como foi tratada neste artigo, é uma das maiores dificuldades encontradas pelos surdos na escrita.

$\mathrm{Na}$ linha 2 "Super-Homem passar rápido, rápido", verifica-se a incorporação da LS na repetição da palavra "rápido". Em Libras, a intensidade é realizada por meio da repetição do sinal e do parâmetro marcador não manual (MNM) ou expressão facial. Por isso, ao invés de o aluno escrever "muito" ou "super", que seria o código esperado em LP, ele lembra a forma como se realiza este elemento na LS.

Neste sentido, Duarte e Padilha (2012, p.319) enfatizam que "precisamos transpor estas ricas informaçôes estruturais da LS para o papel sem 'distorcer" as estruturas da LP. E vice-versa, pensar na representatividade da modalidade escrita de LP com diferentes elementos não existentes em LS". Essas autoras, ao analisarem uma sentença em que há "gostar muito", explicam que "usuários da LS dificilmente usarão o sinal para 'muito' e sim a aplicabilidade da intensidade sobre o verbo gostar, através da expressão facial, movimento e velocidade do verbo apresentado [...]" (Op. cit. p.318).

Tendo em vista este aspecto da Libras, em todo o texto é possível verificar uma quase completa ausência de pontuação. Como mencionamos, a pontuação é um aspecto que depende da entonação e, em Libras, a entonação é marcada pelas expressões faciais. Ainda, o texto escrito por esse aluno apresentou poucas inadequações de ortografia, segundo a norma vigente em português, apenas nas palavras: "A cabou" (linha 5), "corgem" (linha 7) e "Supes-Homem" (linha 19). Fernandes (2007, p.11) explica que "o fato de o sujeito surdo memorizar as palavras na globalidade, acarreta trocas nas posições ou omissóes de letras".

Por fim, analisaremos o último texto, que trata de uma produção conjunta, proposta pela professora de LP e, depois, publicada em um jornal da escola. A forma de apresentação difere das demais, pois não tivemos acesso à produção original. 
Texto VI: O texto escrito em grupo pelos alunos "E", "L", "R", "R1" e "V" quando cursavam o $2^{\circ}$ ano do ensino médio, em 2011.

\section{SURDOS X OUVINTES ${ }^{5}$}

02. Nós surdos, $R, E, R$, L e V começar estudar com ouvintes 5 a série. Nós perceber que nenhum 03. colega tem preconceito. Nós surdos sempre fazer trabalho, atividade junto com ouvintes. Professores 04. e colegas sempre respeitar língua libras. Também muitos colegas aprender libras. Nós surdos ter 05. orgulho porque nenhum reprovar nenhuma matéria, porque felizmente, nós sempre acompanhados 06. intérprete E. Nós sempre aprender verdadeiramente conteúdos. Também nós participar aulas. 07. Professores reconhecer diferente língua por isso avaliação diferente, porque tem livre decreto $n^{\circ}$ 08. 5.626/2002, explica surdos precisa prova diferente. Nós opiniāo inclusão preciso ser sempre com 09. ouvintes, mas preciso presença intérpretes, porque também é direito pessoas surdas.

10. Professores sempre acreditar capacidade surdos, por isso muito valor surdos. Nós, surdos, sempre 11. viajar jogos, sempre ganhar medalhas. Professores felizes resultado.

12. Tem professores todo ano escolher nossa turma porque tem surdos. Eles gostam ensinar surdos, mas 13. tem professores nenhum escolher turma com surdos, porque medo? Não sabe porque. ( $R, E$, $R, L, R 1$ e V)

Esse texto foi produzido pelo grupo de surdos do $2^{\circ}$ ano do ensino médio para uma das ediçōes de um jornal, criação de uma professora de LP. O tema da edição era "inclusão", por isso a professora envolveu toda a turma (surdos e ouvintes).

Nesta produção, verifica-se que os alunos já conseguem fazer uso de alguns conectivos: "atividade junto com ouvinte" (linha 3); "Professores e colegas" (linhas 3 e 4). Há também uma breve noção de conjugação de verbos. Observemos como escreveram, por exemplo, o verbo TER no decorrer do texto: "nenhum colega tem preconceito" (linhas 2 e 3); "porque tem livre decreto" (linha 7); "nossa turma porque tem surdos" (linha 12); "mas tem professores" (linhas 12 e 13). Em todas estas frases o verbo TER foi empregado corretamente. Entretanto, nas linhas 4 e 5, este mesmo verbo ainda foi empregado em sua forma infinitiva: "Nós surdos ter orgulho". Nas frases, citadas anteriormente, quando a conjugação foi utilizada em sua forma padrão, os alunos precisaram trocar apenas uma letra para obter a conjugação

5 Disponível em: http://www.ivyarthursilva.seed.pr.gov.br/redeescola/ escolas/25/1150/20/arquivos/File/GazetaArthuredicao4.pdf. Acesso em 10/11/2013. 
ideal "ter" por "tem". Já na frase "Nós surdos ter orgulho" (linhas 4 e 5) o verbo precisaria ser empregado na $3^{\text {a }}$ pessoa do plural "temos", fato que não é levado em conta na produção dos alunos. O Decreto citado no texto é do ano de 2005 e não de 2002 (linha 8).

Ao analisar o texto, de forma geral, parece possível a sua leitura e compreensão por parte de qualquer pessoa, mas também é possível que os olhos recaiam apenas nas "falhas". Como ressaltamos no início deste texto, ao fazermos esta análise não estamos considerando os elementos linguísticos apontados como falhas na produção escrita dos alunos, mas destacando como ocorre o processo de aquisição da escrita envolvendo duas línguas. Fernandes (2007, p.104) declara que "essa escrita típica e singular é tratada de forma marginal e consiste no vetor da exclusão e das avaliações arbitrárias a que são submetidos alunos surdos na escola”.

Desta forma, reprovar alunos surdos porque não obedecem às normas cultas da LP, sem antes entender os motivos que os levam a escrever desta ou daquela forma, não parece muito coerente. O ideal é que todos os professores e a equipe escolar recebam orientaçóes sobre a cultura linguística das pessoas surdas para que, assim, não cometam injustiças em relação à avaliação dos textos desses alunos.

De acordo com Fernandes (2007, p.17):

Um olhar diferenciado nas produções escritas de alunos surdos é ponto de partida para concretizar, na prática, o diálogo com as diferenças, respeitando as possibilidades e limitações de seu aluno, para valorização de sua identidade surda.

Conforme descrito acima, em relação à LP, os surdos sentemse praticamente estrangeiros em seu próprio país. Por isso, torna-se extremamente importante favorecer o processo de aquisição da Libras e o desenvolvimento da linguagem escrita destas crianças o mais cedo possível. Dependendo do grau da surdez e da detecção precoce do problema, alguns surdos conseguem desenvolver uma linguagem escrita muito próxima ao português padrão. 


\section{CONSIDERAÇÕES FINAIS}

A Libras, embora brasileira e reconhecida como língua oficial, não deixa de ser uma "outra língua" em território nacional, o que causa contradições principalmente com o português tradicional escrito. Assim, mesmo oficializada no Brasil e inserida como disciplina curricular obrigatória nos cursos de fonoaudiologia e licenciatura do ensino superior, conforme determina o Decreto No 5.626/2005, ainda é desconhecida pela maioria da população que não tem contato com a comunidade surda. Esta falta de conhecimento é uma das principais causas da marginalização social que os surdos sofrem até hoje.

A metodologia bilíngue foi apresentada como um modelo que, devidamente empregado, pode trazer resultados positivos na Educação de surdos, pois possibilita a interação entre as duas línguas, Libras e Português, concomitantemente.

Nos textos analisados, observa-se que há uma independência sintática entre a Libras e a LP. Alguns elementos usados na LP, falada e escrita, como: artigos, conjunçôes, preposições e alguns tipos de verbos não são usados em Libras. Essa diferença linguística deve ser levada em consideração pelo professor quando este se confrontar com um texto escrito pelo surdo.

Professores e pessoas que se relacionam com surdos precisam considerar que estão lidando com sujeitos que falam outra língua e, por isso, buscar entender as diferenças linguísticas e as peculiaridades de sua escrita. Todo professor envolvido com a Educação de surdos precisa ter noções mínimas de como agir frente a esse aluno especial, conhecer suas especificidades, sua cultura e reconhecer seu direito constitucional de aprender os conteúdos escolares, sem ser discriminado.

A criação de escolas bilíngues tem sido a principal reivindicação dos movimentos do povo surdo. Porém, até a criação dessas escolas será um longo processo. Enquanto isso, os alunos surdos ainda continuam seus estudos nas escolas regulares de ensino junto com alunos ouvintes, sendo que é direito desses alunos o acesso aos conteúdos e a todo conhecimento por meio da sua língua natural.

Entretanto, é preciso reconhecer que o surdo é considerado um sujeito bicultural, pelo fato de vivenciar situações linguísticas e práticas cotidianas desencadeadas pelas duas línguas, LS e LP. Ele não está inserido em um mundo apenas de surdos. $\mathrm{O}$ seu acesso a todos os meios de interação, como 
a convivência social, placas de trânsito, tecnologia, manuais de instruções e outros implicam que ele interaja com o mundo que o cerca. Nesse sentido, entende-se que o surdo precisa ter competência em ambas as línguas, Libras e LP, tanto no âmbito acadêmico quanto social, ainda que com a LP seja apenas na modalidade escrita.

A partir das análises dos textos produzidos pelos alunos surdos e com base na metodologia utilizada pela professora, bem como dos estudos relacionados à surdez, evidenciou-se a importância de o professor levar em conta os seguintes aspectos:

A criança surda só iniciará seu aprendizado de uma língua escrita após dominar a sua L1, neste caso a LS;

O aluno surdo não estará necessariamente alfabetizado se apenas copiar do quadro ou dos colegas e não associar o que escreve com o seu significado. A cópia e reprodução de palavras ou textos não garantem o conhecimento;

A avaliação dos textos escritos pelos surdos deve considerar a interferência de aspectos estruturais da LS;

A presença do professor bilíngue e do tradutor/intérprete de Libras em sala de aula é fundamental para que o aluno surdo tenha acesso efetivo a todos os conteúdos, desde que o aluno apresente fluência na LS.

\section{REFERÊNCIAS}

BRASIL. Decreto Federal No 5.626, de 22 de dezembro de 2005. Dispõe sobre a Língua Brasileira de Sinais - Libras, e o art. 18 da Lei no 10.098, de 19 de dezembro de 2000. Diário Oficial da República Federativa do Brasil, Brasília, 23 dez. 2005.

BRASIL. Política Nacional de Educação Especial na Perspectiva da Educação Inclusiva. MEC/SEESP, 2008. Disponível em: http://portal.mec.gov.br/arquivos/pdf/ politicaeducespecial.pdf. Acesso em 15/05/2014.

BRASIL. Relatório do grupo de trabalho, designado pelas portarias no 1.060/2013e no91/2013, contendo subsídios para a política linguística de educação bilíngue - língua brasileira de sinais e língua portuguesa. Brasília. MEC/SECADI, 2014.

CAPOVILLA, F. C.; RAPHAEL, W. D. Dicionário Enciclopédico Ilustrado Trilingue. Língua de Sinais Brasileira. Vol. II: sinais de M a Z. 3.ed. São Paulo: Edusp, 2008. CARVALHO, R. E. Educação Inclusiva: com os pingos nos “is". Porto Alegre: Mediação, 2010.

DUARTE, A. S.; PADILHA, S. de J. Relações entre língua de sinais e língua portuguesa em materiais didáticos: a notação pelos números semânticos. ReVEL, v.10, n.19, p.309-326, 2012. Disponível em: http://www.revel.inf.br/files/d2325 7 faea13decda650628084ff88c0.pdf. Acesso em 07/09/2013. 
FERNANDES, S. Educação bilingue para surdos: desafios à inclusão. Curitiba: SEED/SUED/DEE, 2006.

FERNANDES, S. Critérios diferenciados de avaliação na Lingua Portuguesa para estudantes surdos. 2.ed. Curitiba: SEED/SUED/DEE. 2002.

FERNANDES, S. Avaliação em Lingua portuguesa para alunos surdos: algumas consideraçōes. Curitiba, SEED/SUED/DEE, 2007.

FERNANDES, S. Comunicação em Lingua Brasileira de Sinais-Libras. 2.ed. Universidade Federal do Paraná-UFPR. Curitiba, 2012.

GARCÊZ, R. L. Educação bilíngue para surdos segundo pesquisadores linguistas e comunidade surda. Revista da FENEIS, n.45, set/nov. 2011.

GOLDFELD, M. A criança surda: linguagem e cognição numa perspectiva sóciointeracionista. 2.ed. São Paulo: Plexus, 2002.

GUARINELLO, A.C.; MASSI, G.; BERBERIAN, A. P. Surdez e linguagem escrita: um estudo de caso. Rev. Bras. Ed. Esp., Marília, v.13, n.2, p.205-218, 2007. Disponível em: http://www.scielo.br/pdf/rbee/v13n2/a05v13n2.pdf. Acesso em 10/02/2014.

LACERDA, C. B. F. de. Um pouco da história das diferentes abordagens na educação de surdos. Caderno Cedes, vol.19, n.46. Campinas, 1998.

LESSA-DE-OLIVEIRA, A. S. C. Libras escrita: o desafio de representar uma língua tridimensional por um sistema de escrita linear. ReVEL, v.10, n.19, 2012. Disponível em: http://www.revel.inf.br/files/4566006ab74ecff8dc54d92e9649 eb86.pdf. Acesso em 07/05/2014.

LIMA-SALLES, H. M. M. \& VIANA, A. C. C. Estudo da interlíngua de surdos usuários de Língua de Sinais Brasileira na aquisição de português (L2): nominais nus e definidos genéricos. Estudos da Lingua(gem). Vitória da Conquista v.8, n.1 p.241-264, 2010. Disponível em: http://www.estudosdalinguagem.org/seer/index. php/estudosdalinguagem/article/viewArticle/181. Acesso em 22/05/2014.

MARCONI, M. de A.; LAKATOS, E. M. Técnicas de pesquisa: planejamento e execução de pesquisas, amostragens e técnicas de pesquisa, elaboração, análise e interpretação de dados. 3.ed. São Paulo: Atlas, 1996.

MOURA, M. C. de. O surdo: caminhos para uma nova identidade. Rio de Janeiro: Revinter, 2000.

PARANÁ. Instrução N.o 002/2008 - SUED/SEED, 2008. Disponível em: http:// www.educacao.pr.gov.br/arquivos/File/instrucoes/instrucao022008sued.pdf. Acesso em 26 de maio de 2014.

PERLIN, G.T.T. Identidades Surdas. In: SKLIAR, C. (Org.). A surdez: um olhar sobre as diferenças. 4.ed. Porto Alegre: Mediação, 2010. 
RESENDE, P. Política de inclusão. O Globo. Rio de Janeiro. 29 de março de 2011. Disponível em: http://oglobo.globo.com/rio/leia-artigo-da-pedagoga-patriciarezende-sobre-politica-de-inclusao 2804129. Acesso em 21 de maio de 2014.

SALLES, H. M. M. L; FAULSTICH, E; CARVALHO, O. L. C.; RAMOS, L. Ensino de Lingua Portuguesa para Surdos: caminhos para a prática pedagógica. Secretaria de Educação Especial. Vol. 2. Brasília: MEC/SEE/SEESP, 2002.

SANTOS, F. M. A. O processo de aprendizagem da escrita do português por surdos: singularidades e estratégias facilitadoras. Inventário (Universidade Federal da Bahia. Online), v.8, p.1-16, 2011. Disponível em: http://www.inventario.ufba. br/08/O\%20processo\%20de\%20aprendizagem\%20corrigido.pdf. Acesso em $17 / 05 / 2014$.

STREIECHEN, E. M. LIBRAS: aprender está em suas mãos. Curitiba: CRV, 2013. STUMPF, M. R. Mudanças estruturais para uma inclusão ética. In: QUADROS, R. M. de. (Org.). Estudos Surdos III. Petrópolis: Arara Azul, 2008.

STUMPF, M. R. Aprendizagem de Escrita de Lingua de Sinais pelo sistema SignWriting: Línguas de Sinais no papel e no computador. Porto Alegre: UFRGS, CINTED, PGIE, 2005.

Data de submissão: 26/02/2014. Data de aprovação: 28/05/2014. 
